\title{
Management of disrupted sternotomy
}

\author{
AC ROY, JRH PENHALL, EWJ CAMERON \\ From the Department of Cardiothoracic Surgery, The Royal Infirmary, Edinburgh
}

ABSTRACT Seventeen out of 929 consecutive patients $(1.8 \%)$ who underwent open-heart surgery during the last three years developed dehiscence of the sternotomy. Infection was the most common cause of dehiscence and occurred more often after reopening of the incision to control bleeding or relieve tamponade. We describe a one stage closure which was used in all 17 cases. A successful result was obtained in 16 cases, discharge from hospital occurring between 21 and 51 days after closure.

Whether caused by wound infection or, less commonly, by primary non-union of the sternum, disruption of the wound leads to dehiscence of the skin and soft tissue layers anterior to the sternum, separation of the now mobile halves of the divided sternum and exposure of the mediastinum. Reclosure of the wound is mandatory. In this report a method of closure is described and the results obtained with this technique in a series of 17 patients are described.

\section{Surgical technique}

The skin and presternal fascial layers, if not already completely dehiscent, are separated throughout the length of the wound (fig 1). Often the closure of the linea alba is intact in which case the fascial layers in the epigastrium are left undisturbed. The material used (usually wire) to approximate the sternal fragments at primary closure is removed. If the subjacent pericardial cavity is sealed off from the general wound, the sealing layer is not disturbed. It is rare for the pleural cavity to be open to the wound. No attempt is made to close the pericardial cavity if it communicates with the anterior mediastinum. The least manipulation possible is used in management of the wound in order to leave undisturbed the granular layer which covers the wound surface. Any necrotic or foreign material lying free in the wound is removed, but no debridement is performed. A corrugated $250 \mathrm{~mm} \times 25 \mathrm{~mm}$ drain is placed posterior to the whole length of the sternum and emerges at the inferior end of the wound. At least 12 double peristernal no 2 Dexon sutures are placed, passing through the intercostal spaces, avoiding injury to the internal thoracic

Address for reprint requests: Mr EWJ Cameron, Department of Cardiothoracic Surgery, The Royal Infirmary, Lauriston Place, Edinburgh EH3 9YW.

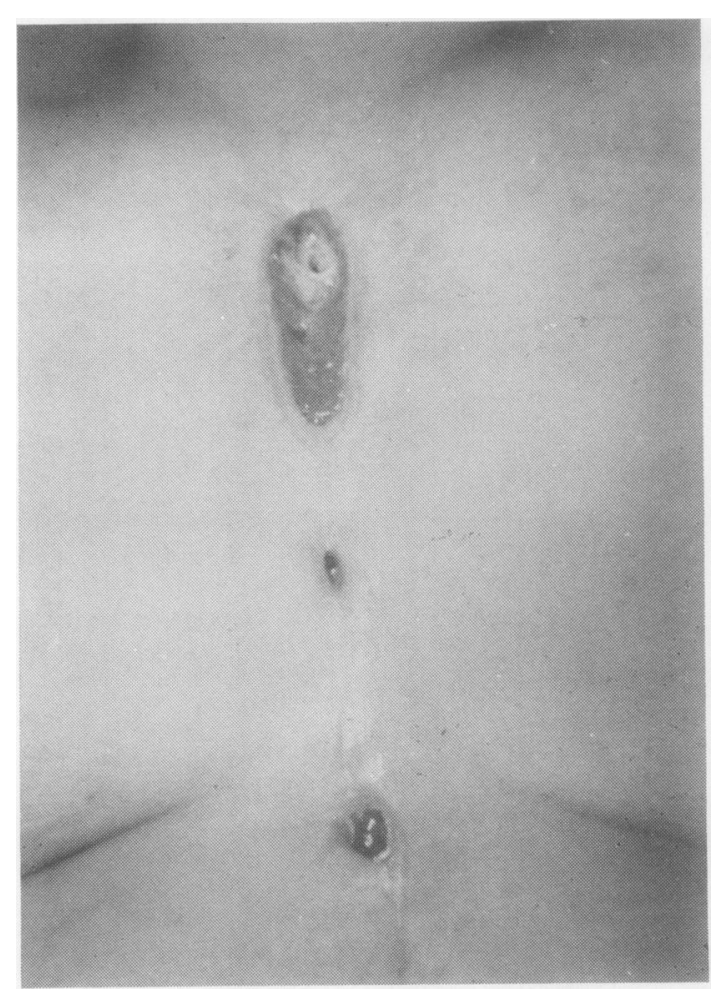

Fig 1 External appearance of sternotomy wound dehiscence.

vessels (fig 2). The sutures are tied one by one, keeping traction all the time on the untied crossover thread ends on both sides. The soft tissue including the skin is closed in one layer (interrupted mattress) with no 1 nylon (fig 3). The skin sutures are left for three weeks. If the pleura is open a 676 


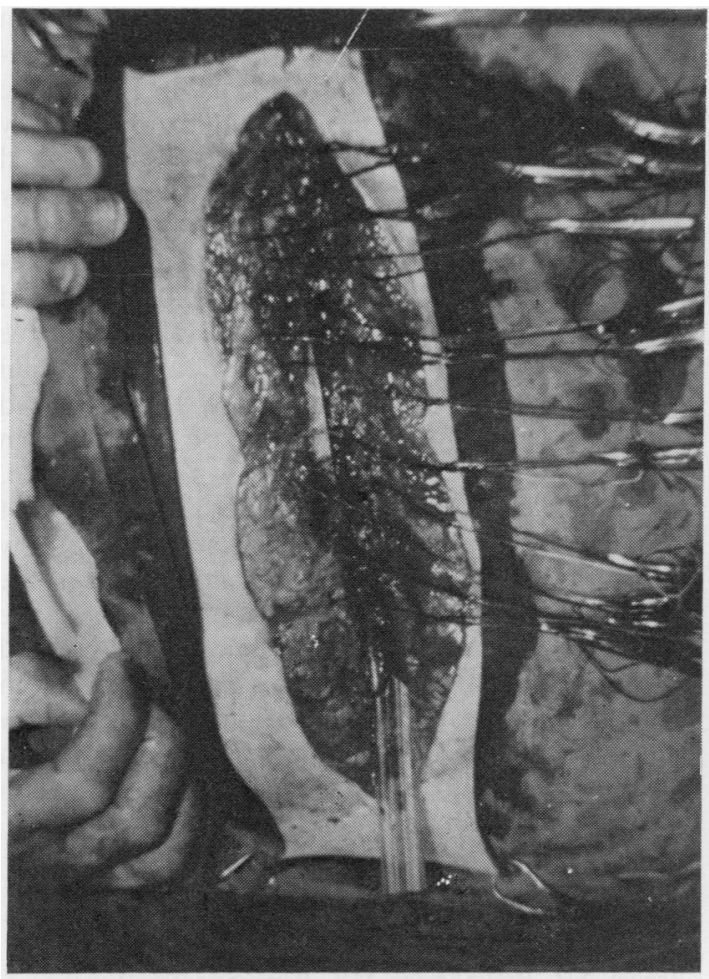

Fig 2 Open wound with dependent drain and peristernal dexon (no 2) sutures in place.

separate tube drain is placed in the pleural cavity, connected to an under water seal drainage bottle. The pleural drain is removed when drainage is minimal and the lung is expanded. The mediastinal corrugated drain is removed by daily shortening when the patient is apyrexial and drainage is minimal. The patient is given systemic antibiotics as determined by culture and sensitivity of the organism grown from the wound.

\section{Results}

In the present series 17 patients had sternotomy wound dehiscence out of 929 sternotomies $(1 \cdot 8 \%)$. There was one failure of management out of the 17 patients. The dehiscence recurred because of continuing infection at the suture line in the ascending aorta. In the other 16 patients satisfactory wound healing was achieved with firm union of the sternal fragment. It took from 21 to 51 days for the wound to heal. Infection caused the dehiscence in 15 out of 17 patients, and there were two cases of primary non-union. In 14 out of the 17 cases the dehiscence followed reopening of the chest

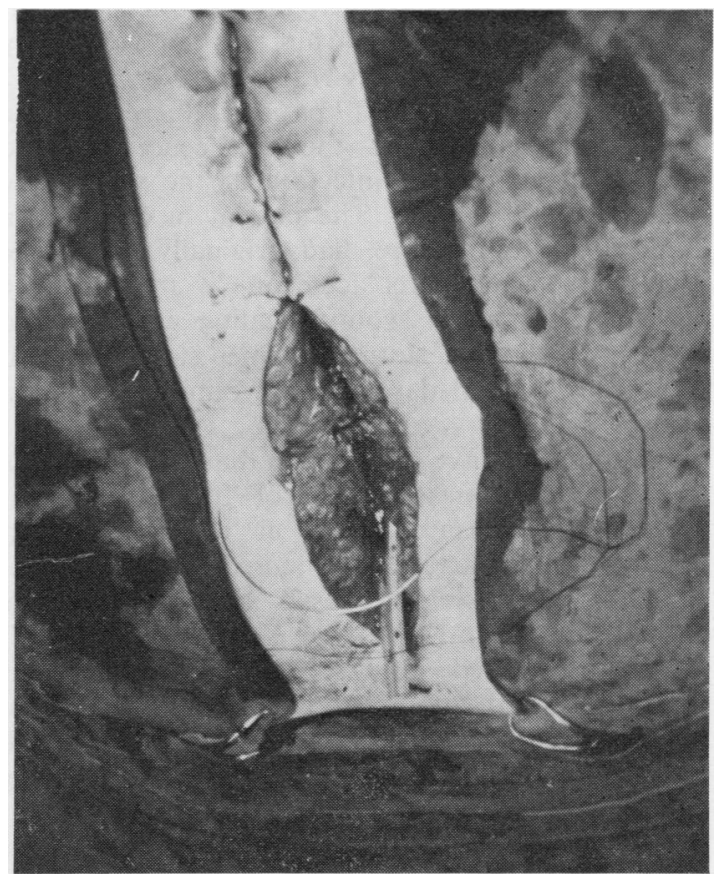

Fig 3 Closure of skin and subcutaneous tissue in one layer with interrupted nylon.

to deal with postoperative haemorrhage. Fourteen cases of dehiscence occurred in a total of 48 cases of reopening whereas there were only three in a total of 881 sternotomies without reopening $(p<0.001$ ).

\section{Discussion}

Dehiscence of the median sternotomy is variously stated to occur in $0.5 \%$ to $5 \%$ of cases. ${ }^{1}$ In the present series it occurred in $1.8 \%$ of cases.

Bryant et $a l^{2}$ recommended mediastinal debridement and irrigation with antibiotic solution. Other descriptions of one stage closure of dehiscence concentrated on the technique of reapproximation of the sternal fragments. Le Veen et $a^{3}$ used a peristernal nylon band, Santos et $a l^{4}$ a peristernal Kirchner wire, Robicsek et $a l^{5}$ a more complex technique involving figure of eight sutures around the costal cartilages, and Moghissi ${ }^{6}$ a peristernal wire brought out through the skin like an all layer tension suture. Dependent drainage of the mediastinum is not referred to in these descriptions. Culliford et $a l^{7}$ reported 39 cases of sternal or costosternal infection in a series of 2594 patients (incidence $1.5 \%$ ). Thirty-two patients were treated by a technique of debridement, primary closure, and antibiotic irrigation, whereas the remaining seven 
patients underwent more radical debridement followed by secondary closure of the wound by granulation. The mortality rate was $10 \%$.

In the present series of 17 patients, there was one failure of management-the dehiscence recurred because of continuing infection at the suture line in the ascending aorta. The patient in question, a diabetic in renal failure, had originally undergone urgent aortic valve replacement. In the other 16 patients, satisfactory wound healing was achieved with firm union of sternal fragments. However, it took from 21 to 51 days for the wounds in question to heal.

Bryant $e t a l^{2}$ have commented that reopening of a median sternotomy to control haemorrhage or release cardiac tamponade in the early postoperative phase leads to an increased incidence of subsequent dehiscence caused by infection. The experience in the present series is similar. This result is to be expected since sternotomy reopening is often performed with such urgency that the normal rules of sterile technique are not fully obeyed. Recognition and avoidance of this predisposing factor should be achieved whenever possible.

Early detection and correction of clotting defects avoids the costly results of excessive postoperative haemorrhage. Each cardiotomy, whether for intracardiac repair or for cannulation should be inspected carefully before closure, as should suture lines in the aorta or pulmonary artery. Pericardial vessels require attention. Extreme care must be taken in passing the wires about the sternum, since the internal thoracic artery does not conform with that usually described anatomically. Careful inspection for bleeding points should always be made after all wires have been placed.

Limitation of perfusion time is not always possible but efforts should be made to shorten operating time. Protamine rebound is easily prevented by giving the calculated amount of Protamine in divided doses, erring on the side of using too little rather than too much. If uncertainty exists as to the rate or course of postoperative bleeding, the patient should be observed in the operating room after skin closure and a decision made on the need for reopening. The incision should be made before the removal of sterile drapes. The significance of hasty reoperation in an unsterile area should be emphasised as an important factor predisposing to sternotomy dehiscence.

Perhaps when such circumstances attend a reopening, the method of sternotomy closure should be altered-for example, by the use of absorbable peristernal sutures, the retention of a mediastinal drain for a longer period, the use of interrupted technique for the superficial layers of the wound in an effort to prevent the effects of wound infection, and prophylactic antibiotics to cover a wide range of organisms. In two patients in this series, sternotomy dehiscence was caused by primary non-union of the divided sternal fragments and in one of these the sternal wire sutures had cut through the soft cortical bone of an elderly patient. This complication can probably be prevented at the original operation by using material other than wire, for example, a peristernal nylon band or peristernal closure with silk, to reapproximate the sternum.

\section{References}

${ }^{1}$ Brown AH, Braimbridge MV, Panagopoulos P, Sabar F. The complications of median sternotomy. $J$ Thorac Cardiovasc Surg 1969;58:189-97.

${ }^{2}$ Bryant LR, Spencer FC, Trinkle JK. Treatment of median sternotomy infection by mediastinal irrigation with an antibiotic solution. Ann Surg 1969;169:914-20.

${ }^{3}$ LeVeen HL, Piccone VA. Nylon-band chest closure. Arch Surg 1968;96:36-9.

${ }^{4}$ Santos G, Cook WA, Frater WM. Reclosure of sternotomy disruption produced by hiccups. Chest 1974;66:189-90.

${ }^{5}$ Robicsek F, Daugherty HK, Cook JW. The prevention and treatment of sternum separation following open-heart surgery. J Thorac Cardiovasc Surg 1977;73:267-8.

${ }^{6}$ Moghissi K. Median sternotomy wound disruption. $J$ Roy Coll Surg Edinb 1977;22:156-7.

${ }^{7}$ Culliford AT, Cunningham JN Jr, Zeff RH, Isom OW, Teiko P, Spencer FC. Sternal and costosternal infections following open-heart surgery: a review of 2594 cases. $J$ Thorac Cardiovasc Surg 1976;72:714-26. 